\title{
BM] Global Health National survey of Ebola-related knowledge, attitudes and practices before the outbreak peak in Sierra Leone: August 2014
}

\author{
Mohamed F Jalloh, ${ }^{1,2,3}$ Paul Sengeh, ${ }^{2}$ Roeland Monasch, ${ }^{4}$ Mohammad B Jalloh, ${ }^{5}$ \\ Nickolas DeLuca, ${ }^{6}$ Meredith Dyson, ${ }^{7}$ Sheku Golfa, ${ }^{4}$ Yukiko Sakurai, ${ }^{4}$ \\ Lansana Conteh, ${ }^{8}$ Samuel Sesay, ${ }^{8}$ Vance Brown, ${ }^{1}$ Wenshu Li, ${ }^{1}$ Jonathan Mermin, ${ }^{9}$ \\ Rebecca Bunnell ${ }^{1}$
}

\begin{abstract}
To cite: Jalloh MF, Sengeh $P$, Monasch $\mathrm{R}$, et al. National survey of Ebola-related knowledge, attitudes and practices before the outbreak peak in Sierra Leone: August 2014. BMJ Glob Health 2017;2:e000285. doi:10.1136/ bmjgh-2017-000285
\end{abstract}

Handling editor Alberto GarciaBasteiro

Received 8 January 2017 Revised 16 May 2017 Accepted 17 May 2017

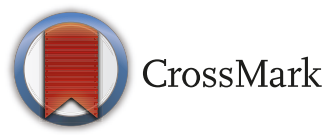

For numbered affiliations see end of article.

Correspondence to Mohamed F Jalloh; yum8@cdc.gov

\section{ABSTRACT}

Background The 2014-2015 Ebola epidemic in West Africa was the largest ever to occur. In the early phases, little was known about public knowledge, attitudes and practices (KAP) relating to Ebola virus disease (Ebola). Data were needed to develop evidence-driven strategies to address gaps in knowledge and practice.

Methods In August 2014, we conducted interviews with 1413 randomly selected respondents from 9 out of 14 districts in Sierra Leone using multistage cluster sampling. Where suitable, Ebola-related KAP questions were adapted from other internationally validated questionnaires related to infectious diseases.

Results All respondents were aware of Ebola. When asked unprompted, $60 \%$ of respondents could correctly cite fever, diarrhoea and vomiting as signs/symptoms of Ebola. A majority of respondents knew that avoiding infected blood and bodily fluids $(87 \%)$ and contact with an infected corpse $(85 \%)$ could prevent Ebola. However, there were also widespread misconceptions such as the belief that Ebola can be prevented by washing with salt and hot water (41\%). Almost everyone interviewed (95\%) expressed at least one discriminatory attitude towards Ebola survivors. Unprompted, self-reported actions taken to avoid Ebola infection included handwashing with soap (66\%) and avoiding physical contact with patients with suspected Ebola (40\%).

Conclusion Three months into the 2014 Ebola outbreak in Sierra Leone, our findings suggest there was high awareness of the disease but misconceptions and discriminatory attitudes toward survivors remained common. These findings directly informed the development of a national social mobilisation strategy and demonstrated the importance of KAP assessment early in an epidemic.

\section{INTRODUCTION}

The 2014-2015 Ebola virus disease (Ebola) epidemic in West Africa was the largest outbreak of Ebola in recorded history. By the end of the epidemic, 28646 cases and over 11000 deaths were officially reported. ${ }^{1}$ By mid-August 2014, when the present assessment was being conducted, Sierra Leone had recorded nearly 730 confirmed cases of Ebola. ${ }^{2}$ The epidemic was also affecting Guinea and Liberia, and was already the largest outbreak of Ebola since the first identified case of Ebola in Zaire in 1976. ${ }^{3}$ In the initial months of the epidemic, response efforts were limited and poorly coordinated. ${ }^{4}$ Widespread community level social mobilisation efforts had not yet been launched and little was known about public knowledge, attitudes and practices (KAP) related to Ebola. ${ }^{5}$ The importance of public education and community engagement in outbreak responses is well established ${ }^{6-9}$ and KAP surveys have helped to inform many outbreak responses. ${ }^{10-14}$

Other studies have also measured Ebola-related KAP within different populations in sub-Saharan Africa ${ }^{15-25}$ and other parts of the world. ${ }^{26-30}$ However, few national-level KAP studies have been conducted in Ebola affected countries during periods of active transmission. The present study represents the first national Ebola KAP survey in Sierra Leoneconducted in August 2014-within the first 3 months of a prolonged epidemic that lasted over a year. In June 2014, the International Federation of Red Cross and Red Crescent Societies (IFRC) conducted a small-scale KAP study with a small convenience sample in the initial epicentres of Kailahun and Kenema districts in Sierra Leone. ${ }^{31}$ The IFRC survey revealed that less than a third of respondents knew that avoiding contact with corpses of infected persons is a way of preventing the transmission of Ebola. ${ }^{18}$ While this assessment in Kenema and Kailahun provided useful information less than 1 month into the outbreak in these districts, a national KAP study was needed to inform prevention efforts 


\section{Key questions}

\section{What is already known about this topic?}

- Previous studies have examined knowledge, attitudes and practices (KAP) related to Ebola virus disease among different populations but they were limited to subnational geographical areas and conducted after the peak of an outbreak or in non-outbreak settings.

- Ebola-related KAP studies have revealed varying levels of knowledge and misconceptions regarding transmission, prevention and treatment of the disease.

- Improvements in health-seeking behaviours and modifications to traditional burial practices were important to containing Ebola transmission in West Africa.

\section{What are the new findings?}

- We describe how this first national KAP survey of the 2014-2015 Ebola epidemic in West Africa was used in real-time during the early phase of the outbreak in Sierra Leone to inform risk communication, social mobilisation and health promotion interventions aiming to reduce Ebola transmission.

- Nearly everyone interviewed held at least one discriminatory attitude towards Ebola survivors as well as widespread misconceptions in the early months of the outbreak in Sierra Leone.

- Respondents self-reported frequent handwashing and avoidance of physical contact, and wanted to learn about Ebola prevention and treatment/medical care.

- Radio, religious venues and health workers were the most popular sources of receiving Ebola-related information in the early months of the outbreak.

\section{Recommendations for policy}

- Identifying and addressing the public's misconceptions regarding disease transmission, prevention and medical care should be an important aspect of early outbreak response.

- Social implications of an outbreak, such as stigmatisation of affected persons, need to be addressed as part of overall response efforts.

- Rapidly conducting KAP assessments close to the onset of an outbreak informs immediate response measures and could help facilitate prevention-related behaviour change during future outbreaks.

country-wide. The present KAP assessment was therefore designed and implemented by the Sierra Leone National Social Mobilisation Pillar, supported by FOCUS 1000, UNICEF, Catholic Relief Services (CRS) and US Centers for Disease Control and Prevention (CDC) as a baseline assessment in August 2014 to inform social mobilisation and community engagement strategies on Ebola prevention, control and treatment in Sierra Leone.

Specific objectives of this KAP assessment were to quantitatively examine public KAP related to Ebola, identify barriers that hinder the containment of the outbreak, and use the data to set a baseline and inform development of national risk communication and social mobilisation strategies.

Throughout the Ebola response, the Government of Sierra Leone, development partners and community leaders placed a major focus on educating the public on how to prevent the transmission of Ebola as well as on encouraging people to promptly seek medical care in the event that they experience signs and symptoms associated with Ebola. ${ }^{5}$ As the outbreak widened, the focus of community engagement also included educating the public on protective measures while waiting for help to arrive-such as isolating suspected patients. ${ }^{8}$ Furthermore, community engagement efforts gradually placed increased emphasis on shifting burial and funeral practices that involved contact with corpses. Despite these efforts, public education and social mobilisation campaigns were met with varied reception from communities. Addressing myths, misconceptions and misinformation about the disease was an important aspect of the Ebola response in Sierra Leone. ${ }^{58932}$

Ebola is primarily transmitted through direct contact with the blood, stool or other bodily fluids of infected persons. The case-fatality rate during the West Africa outbreak was $~ 70 \%,{ }^{33}$ and at the time of the outbreak there was no specific treatment for Ebola except supportive care. Healthcare workers were frequently affected ${ }^{34}$ as were caregivers and persons attending burial ceremonies that involved contact with the deceased body. ${ }^{33}$ Sexual transmission can also occur, and Ebola virus has been detected in semen for months following clinical recovery. ${ }^{35}$ Due to the high likelihood of transmission unless specific precautions are taken, education and behaviour change are essential features of an effective outbreak response-and this effort requires national coverage of behaviour change interventions in situations where Ebola has spread widely, such as in Sierra Leone.

\section{METHODS}

We employed a cross-sectional design survey to assess the public's KAP relating to Ebola in Sierra Leone. The survey covered 9 out of 14 districts in Sierra Leone: Western Rural, Western Urban, Kenema, Kailahun, Bo, Moyamba, Kambia, Port Loko and Koinadugu districts.

We used a multistage cluster sampling procedure with primary sampling units selected via probability proportional to their size (PPS). A sample size ${ }^{i}$ beyond the minimum estimated sample of participants was used in order to attain $95 \%$ confidence level and a confidence interval of $+/-3.5 \%$ given Sierra Leone's estimated population of approximately six million in the most recent National Population and Housing Census at the time. ${ }^{36}$ The sample design was intended to produce national-level estimates. The Sierra Leone 2004 Census List of Enumeration Areas served as the sampling frame for the selection of all enumeration areas. Enumeration areas were randomly selected from nine districts across all four geographical regions in the country.

To select households for interviews, the enumerators used the random walk method, a form of systematic random sampling. ${ }^{37}$ Following informed consent, interviews were conducted with two individuals from each randomly selected

${ }^{\mathrm{i}}$ Sample size estimate-95\% confidence level; level of confidence measure: 1.96; margin of error: 0.035 ; indicator prevalence: 0.5 ; design effect: 1.5 ; expected response rate: $90 \%$; estimated population: 6 million. 
Table 1 Sociodemographic characteristics of respondents, National Ebola KAP survey, Sierra Leone, August 2014 $(n=1413)$

\begin{tabular}{|c|c|c|}
\hline Characteristic & $\mathbf{N}$ & $\%$ \\
\hline \multicolumn{3}{|l|}{ District } \\
\hline Bo & 151 & 11 \\
\hline Kailahun & 130 & 9 \\
\hline Kambia & 120 & 8 \\
\hline Kenema & 139 & 10 \\
\hline Koinadugu & 119 & 8 \\
\hline Moyamba & 127 & 9 \\
\hline Port Loko & 196 & 14 \\
\hline Western Rural & 92 & 7 \\
\hline Western Urban & 339 & 24 \\
\hline Total sample & 1413 & 100 \\
\hline \multicolumn{3}{|l|}{ Sex* } \\
\hline Female & 749 & 53 \\
\hline Male & 655 & 47 \\
\hline \multicolumn{3}{|l|}{ Age category† } \\
\hline 15-24 years & 510 & 37 \\
\hline $25+$ years & 881 & 63 \\
\hline \multicolumn{3}{|l|}{ Education level $\ddagger$} \\
\hline None & 360 & 26 \\
\hline Primary & 188 & 14 \\
\hline Some secondary or higher & 840 & 60 \\
\hline
\end{tabular}

Religious affiliation§

\begin{tabular}{lll} 
Islam & 901 & 64 \\
Christianity & 501 & 36 \\
\hline
\end{tabular}

*Missing values for $\operatorname{sex}=9$.

†Missing values for age $=21$.

$\ddagger$ Missing values for education $=25$.

$\S$ No religious affiliation=1; declined to answer=5; missing values $=5$.

KAP, knowledge, attitudes and practices.

household. All household heads were selected given their influential role on the decisions and practices within the household. In addition, given that the majority of the household heads in Sierra Leone are older men, we randomly selected another participant from the household listing who was either an adult woman (ages 25 years and above) or a young person between ages 15 years and 24 years. Enumerators used six-sided dice to generate a random number to select from the eligible household list.

The survey questionnaire (see online supplementary appendix 1) included both prompted direct questions as well as unprompted open-ended questions that allowed for multiple responses. Core Ebola KAP domains in the questionnaire included sources of information, knowledge about Ebola, behavioural intentions, prevention practices and attitudes towards survivors. The indicators used to assess Ebola KAP were informed by lessons learnt from similar KAP studies on other communicable diseases, especially HIV/AIDS. $.^{10-12} 38-42$ In suitable instances (eg, for knowledge and stigma), we adapted indicators and items from the Joint United Nations Programme on HIV/AIDS. ${ }^{40} 41$

On average, questionnaires took approximately 45-60 minutes to administer. Nearly all interviews were conducted in Krio- the most commonly spoken language in Sierra Leone. Each data collection team comprised four members-one supervisor and three enumerators; all of whom were Sierra Leoneans and from their assigned districts. The enumerators were responsible for administering the questionnaire on a one-on-one basis while supervisors provided quality assurance and control-including the safekeeping of consent forms and completed questionnaires. Each enumerator was expected to complete 10-12 questionnaires per day. In addition to the team supervisors, senior staff from FOCUS 1000 served as regional supervisors to ensure proper quality control. All data collection teams-enumerators and supervisors-participated in a 3-day training workshop and had the opportunity to pretest the questionnaire within a designated community prior to being deployed for field data collection. The training was implemented by staff from FOCUS 1000, UNICEF and CRS.

Data collection took place during 20-26 August 2014. Once data were collected, all questionnaires were then entered into a customised Excel-based system. Double entry verification was performed on randomly selected questionnaires $(n=200)$. The data were subsequently imported into and analysed in SPSS V.22. The data were weighted to adjust for any oversampling or undersampling within districts as per the established PPS. Descriptive statistics were then generated for national level estimates (proportions) and their 95\% CIs.

The assessment protocol was approved by the Sierra Leone Ethics and Scientific Review Committee in the Ministry of Health and Sanitation.

\section{RESULTS}

Of 1460 randomly selected individuals approached by data collectors, 1413 (97\%) respondents from 707 households consented to participate. Of all respondents, 53\% were female; $37 \%$ were between the ages 15 years and 24 years. About a quarter of respondents (26\%) had no formal education. Majority of the respondents (64\%) were Muslim (table 1).

\section{Awareness and risk perception}

All respondents had heard of Ebola prior to the interview. Overall, $78 \%$ of respondents were aware that it is possible to survive and recover from Ebola. Majority of respondents $(58 \%)$ perceived themselves to be at some risk of contracting Ebola (table 2A).

Knowledge of Ebola cause, transmission, signs and symptoms In an open-ended question, the most common perceived cause/origin of Ebola was 'bats, monkeys, 
Table 2 Ebola-related awareness, risk perceptions and knowledge, National Ebola KAP survey, Sierra Leone, August 2014 $(n=1413)^{*}$

\begin{tabular}{|c|c|c|}
\hline Indicator & $\%$ & $95 \% \mathrm{Cl}$ \\
\hline \multicolumn{3}{|l|}{ A-Awareness and risk perception } \\
\hline Heard of Ebola & 100 & 97.7 to 100 \\
\hline Expressed that Ebola existed in Sierra Leone & 97 & 96.1 to 97.9 \\
\hline Aware of possibility to survive and recover from Ebola & 78 & 75.7 to 80.0 \\
\hline Aware of possibility to have Ebola without showing signs/symptoms & 40 & 37.5 to 42.7 \\
\hline Aware of Ebola call centre to report sick persons and deaths & 57 & 54.3 to 59.5 \\
\hline Perceived some risk of contracting Ebola & 58 & 55.1 to 60.2 \\
\hline \multicolumn{3}{|l|}{ B-Knowledge of Ebola cause $†$} \\
\hline Bats/monkeys/chimpanzees/other wild animals & 74 & 71.9 to 76.5 \\
\hline Virus & 42 & 39.6 to 44.8 \\
\hline God or higher power & 2 & 1.1 to 2.5 \\
\hline Witchcraft & 1 & 0.5 to 1.6 \\
\hline \multicolumn{3}{|l|}{ C-Knowledge of Ebola modes of transmission $\ddagger$} \\
\hline Shaking hands with an infected person & 56 & 53.5 to 58.6 \\
\hline Eating 'bush meat' & 52 & 50.0 to 55.2 \\
\hline Other physical contact with an infected person & 50 & 47.2 to 52.4 \\
\hline Sweat of an infected person & 48 & 45.8 to 51.0 \\
\hline Eating fruits likely to have been bitten by bats & 35 & 32.2 to 37.1 \\
\hline Blood of an infected person & 34 & 31.8 to 36.7 \\
\hline Preparing 'bush meat' as a meal & 33 & 30.2 to 35.1 \\
\hline Saliva of an infected person & 33 & 30.1 to 35.0 \\
\hline Urine of an infected person & 27 & 25.0 to 29.6 \\
\hline Faeces of an infected person & 20 & 18.3 to 22.5 \\
\hline Semen or vaginal fluid of an infected person & 19 & 17.3 to 21.4 \\
\hline Breast milk of an infected person & 14 & 12.9 to 16.6 \\
\hline \multicolumn{3}{|l|}{ D-Knowledge of Ebola signs and symptoms§ } \\
\hline Knew three key signs/symptoms of Ebola (fever, diarrhoea, vomiting) & 60 & 57.7 to 62.7 \\
\hline Vomiting (with or without blood) & 83 & 80.6 to 84.5 \\
\hline Diarrhoea (with or without blood) & 73 & 70.7 to 75.4 \\
\hline Fever & 79 & 76.6 to 80.9 \\
\hline Rash & 45 & 42.7 to 47.9 \\
\hline Severe headache & 38 & 35.3 to 40.3 \\
\hline Muscle pain & 23 & 20.9 to 25.3 \\
\hline Weakness & 22 & 19.7 to 24.0 \\
\hline Abdominal pain & 11 & 9.0 to 12.2 \\
\hline
\end{tabular}

*Item-specific sample sizes slightly varied with $<5 \%$ missing values for any item.

†Unprompted/open-ended/multiple selection item.

łUnprompted/open-ended/multiple selection item.

§Unprompted/open-ended/multiple selection item.

$\mathrm{KAP}$, knowledge, attitudes and practices.

and wild animals' (74\%); only 42\% linked Ebola to a 'virus.' Very few respondents mentioned that Ebola is caused by 'God' $(2 \%)$ or 'witchcraft' $(1 \%)$. In response to an unprompted open-ended question, the most frequently cited modes of transmission were: shaking hands with an infected person
(56\%), eating bush meat (52\%) and other physical contact with an infected person $(50 \%)$. Overall, $60 \%$ of respondents could name, without prompting, three key signs/symptoms of Ebola: 'vomiting' $(83 \%)$, 'diarrhea' (73\%) and 'any fever' (78\%) (table 2B-D). 
Table 3 Ebola-related knowledge, behavioural intentions and practices, National Ebola KAP survey, Sierra Leone, August $2014(n=1413)^{\star}$

\begin{tabular}{|c|c|c|}
\hline Indicator & $\%$ & $95 \% \mathrm{Cl}$ \\
\hline \multicolumn{3}{|l|}{ A-Knowledge of Ebola prevention and treatment } \\
\hline Ebola can be prevented by avoiding contact with blood and body fluids & 87 & 85.3 to 88.8 \\
\hline Ebola can be prevented by avoiding funeral/burial involving contact with corpse & 85 & 82.8 to 86.6 \\
\hline Ebola can be prevented by not touching anyone else & 83 & 81.2 to 85.1 \\
\hline Early treatment increases chance of surviving Ebola & 91 & 89.5 to 92.5 \\
\hline Early treatment reduces further Ebola spread within household & 91 & 89.4 to 92.4 \\
\hline \multicolumn{3}{|l|}{ B-Misconceptions of Ebola transmission, prevention and treatment } \\
\hline Ebola can be prevented by bathing with salt and hot water & 41 & 38.7 to 43.9 \\
\hline Ebola can be transmitted through the air & 30 & 27.7 to 32.6 \\
\hline Ebola can transmitted by mosquito bites & 30 & 27.3 to 32.1 \\
\hline Ebola can be treated successfully by spiritual healers & 19 & 16.7 to 20.8 \\
\hline Ebola can be treated successfully by traditional healers & 5 & 4.3 to 6.6 \\
\hline \multicolumn{3}{|l|}{ C-Perceptions of health facilities $\dagger$} \\
\hline Health facility will take care of sick person & 60 & 57.4 to 62.5 \\
\hline Health facility will definitely cure sick person from Ebola & 41 & 38.1 to 43.2 \\
\hline Health facility won't be able to do anything for sick person & 6 & 4.4 to 6.8 \\
\hline Health facility will find way to kill sick person & 6 & 5.1 to 7.7 \\
\hline \multicolumn{3}{|l|}{ D-Perceptions of Ebola treatment centres (ETCs) and quarantine measures } \\
\hline Persons diagnosed with Ebola must be admitted in ETCs & 95 & 94.1 to 96.3 \\
\hline Direct contacts of patient diagnosed with Ebola must be quarantined for 3 weeks & 90 & 88.4 to 91.6 \\
\hline \multicolumn{3}{|l|}{ E-Health-seeking behavioural intentions } \\
\hline Would go to health facility if Ebola suspected & 94 & 92.1 to 94.6 \\
\hline Would go to health facility if had a high fever & 87 & 84.8 to 88.4 \\
\hline \multicolumn{3}{|l|}{ F-Behavioural intentions if family member suspected of Ebolał } \\
\hline Call the hospital/Ebola hotline & 71 & 68.8 to 73.5 \\
\hline Take the person to the hospital & 27 & 24.7 to 29.3 \\
\hline Avoid all physical contact and bodily fluids of that person & 15 & 13.5 to 17.3 \\
\hline Help care for the person at home & 1 & 0.4 to 1.3 \\
\hline \multicolumn{3}{|l|}{ G-Self-reported prevention practices§ } \\
\hline Reported taking some action to avoid Ebola infection & 96 & 94.3 to 96.4 \\
\hline Wash hands with soap and water & 66 & 63.6 to 68.6 \\
\hline Avoid physical contact with everyone & 47 & 43.9 to 49.2 \\
\hline Avoid physical contact with people suspected of Ebola & 40 & 37.4 to 42.5 \\
\hline Avoid crowded places & 37 & 34.7 to 39.7 \\
\hline
\end{tabular}

*Item-specific sample sizes varied slightly with $<5 \%$ missing for any item.

†Unprompted/open-ended/multiple selection item.

fUnprompted/open-ended/multiple selection item.

§Unprompted/open-ended/multiple selection item.

KAP, knowledge, attitudes and practices.

\section{Knowledge of Ebola prevention and treatment}

Knowledge of Ebola prevention and treatment was high among respondents such that nearly everyone knew that Ebola can be prevented by avoiding contact with blood and bodily fluids (87\%) as well as funeral or burials that require contact with the corpse $(85 \%)$. Furthermore, $91 \%$ of respondents expressed that early treatment of
Ebola could increase survival and reduce the chance of transmission within the household (table 3A).

\section{Misconceptions of Ebola transmission, prevention and treatment}

There were widespread misconceptions of Ebola transmission, prevention and treatment. Forty-one per cent 
Table 4 Attitudes towards Ebola Survivors and perceptions of Ebola vaccine and experimental treatment, National Ebola KAP survey, Sierra Leone, August $2014(n=1413)^{*}$

\begin{tabular}{lll}
\hline Indicator & $\%$ & $\mathbf{9 5 \%} \mathbf{C l}$ \\
\hline A-Attitudes towards Ebola survivors & & \\
\hline Student who survived Ebola puts others in class at risk of infection & 66 & 62.9 to 68.1 \\
\hline Would not buy vegetables from shopkeeper who survived Ebola & 69 & 66.5 to 71.4 \\
Would not welcome Ebola survivor into community & 78 & 75.7 to 80.1 \\
\hline Expressed at least one discriminatory attitude towards Ebola survivors & 95 & 93.5 to 95.9 \\
B-Perceptions of Ebola vaccine and experimental treatment & & \\
Would accept an approved Ebola vaccine for self & 90 & 88.7 to 91.8 \\
Would accept an approved Ebola vaccine for children & 90 & 88.1 to 91.4 \\
\hline Would accept experimental Ebola treatment for self & 62 & 59.7 to 64.8 \\
\hline Would accept experimental Ebola treatment for relative & 63 & 60.6 to 65.8 \\
\hline
\end{tabular}

*Item-specific samples sizes varied slightly with $<5 \%$ missing for any item. $\mathrm{KAP}$, knowledge, attitudes and practices.

of respondents expressed that they could protect themselves from Ebola by washing with salt and hot water solution. Nearly a third of respondents expressed that Ebola is transmitted by air $(30 \%)$ and through mosquito bites $(30 \%)$. Moreover, $19 \%$ of respondents perceived that spiritual healers ${ }^{\text {ii }}$ could successfully treat Ebola (table 3B).

\section{Health-seeking behavioural intentions and self-reported prevention practices}

Nearly all respondents (87\%) reported that they would go to a health facility if experiencing a high fever and even more so for suspected Ebola (94\%). Nearly all respondents (96\%) reported taking some preventive action since learning about Ebola. Handwashing with soap was the most prevalent behaviour reported in unprompted response $(66 \%)$, followed by avoiding physical contact with everyone $(47 \%)$. Only $40 \%$ mentioned spontaneously that they try to avoid physical contact with people suspected to have Ebola (table 3C-G).

\section{Attitudes towards Ebola survivors}

Overall, 95\% of respondents expressed at least one discriminatory attitude towards Ebola survivors. For instance, $78 \%$ reported that they would not welcome back an Ebola survivor into the community and 69\% would refuse to buy fresh vegetables from a shopkeeper who survived Ebola (table 4A).

\section{Perceptions of Ebola vaccine and experimental treatment}

Ninety per cent of respondents reported they would accept an approved Ebola vaccine if it were to become available, and $62 \%$ said they would accept experimental treatments that have not been tried in humans (table 4B).

\footnotetext{
${ }^{\mathrm{ii}}$ Spiritual healing defined as: healing processes that involve combination of prayer as well as use of religious texts, materials and other spiritual ceremonies performed by Spiritural Healers.
}

\section{Sources of receiving Ebola-related information}

Radio $(88 \%)$ was the primary Ebola information channel mentioned by respondents of an open-ended question, followed by religious venues such as mosques and churches $(42 \%)$ and house visits by health workers $(26 \%)$ (table 5A). In response to an open-ended question, the most trusted information sources on Ebola were health professionals $(61 \%)$, the Government/Ministry of Health and Sanitation (49\%) and the media (36\%) (table 5B).

\section{Ebola information gaps}

Nearly all participants desired more information about Ebola (93\%) and mentioned specifically wanting to know more about ways to prevent the disease $(53 \%)$ as well as medical care and treatment options for infected persons $(37 \%)$. Lower proportion of respondents wanted more information on Ebola's cause/origin (24\%) or its signs/ symptoms (21\%) (table 5C).

\section{DISCUSSION}

The KAP findings suggest that in August 2014, just three months into the country's outbreak, awareness and preventive behaviours of Ebola were widespread in Sierra Leone, but gaps in knowledge misconceptions and discriminatory attitudes towards Ebola survivors were common. Overall, public knowledge, attitudes and behavioural intentions appeared to be ahead of specific Ebola communication interventions at the time. The findings directly informed the development of a national social mobilisation strategy ${ }^{5}$ and provided a baseline for evaluating Ebola prevention, control and care efforts throughout the remainder of the epidemic.

Prior to this KAP survey, Ebola-related social mobilisation engagements in Sierra Leone lacked the evidence needed to design targeted interventions for prioritised populations using trusted information sources. For example, the primary focus of messages prior to the KAP 
Table 5 Ebola-related information sources, trusted sources, and information gaps, National Ebola KAP survey, Sierra Leone, August $2014(n=1413)^{*}$

\begin{tabular}{|c|c|c|}
\hline Indicator & $\%$ & $95 \% \mathrm{Cl}$ \\
\hline \multicolumn{3}{|l|}{ A-Sources of receiving Ebola-related informationt } \\
\hline Radio & 88 & 86.2 to 89.6 \\
\hline Church/mosque/other religious venues & 42 & 39.1 to 44.3 \\
\hline House visits by health workers & 26 & 23.3 to 27.9 \\
\hline Megaphone public & 24 & 21.6 to 26.0 \\
\hline Television & 21 & 19.2 to 23.4 \\
\hline Internet and social media & 15 & 13.6 to 17.3 \\
\hline Community meetings & 12 & 10.6 to 14.1 \\
\hline Print materials & 8 & 6.7 to 9.5 \\
\hline Mobile phone/textmessages & 0.4 & 0.2 to 0.9 \\
\hline \multicolumn{3}{|l|}{ Radio listenership } \\
\hline Listen to radio everyday & 78 & 76.3 to 80.6 \\
\hline Listen to radio at least once a week & 13 & 11.2 to 14.8 \\
\hline Listen to radio less than once a week & 3 & 2.1 to 3.8 \\
\hline Do not listen to radio & 6 & 4.5 to 6.9 \\
\hline \multicolumn{3}{|l|}{ B-Trusted sources of Ebola-related information $\ddagger$} \\
\hline Health and medical professionals & 61 & 58.6 to 63.7 \\
\hline Government/Ministry of Health and Sanitation & 49 & 46.6 to 51.8 \\
\hline Media & 36 & 33.6 to 38.6 \\
\hline Religious leaders & 10 & 8.3 to 11.3 \\
\hline Relatives and friends & 9 & 7.8 to 10.8 \\
\hline Traditional healers & 0.3 & 0.2 to 0.8 \\
\hline \multicolumn{3}{|l|}{ C-Ebola information gaps§ } \\
\hline Wanted more Ebola-related information on... & 93 & 91.9 to 94.5 \\
\hline Prevention & 53 & 50.8 to 55.0 \\
\hline Medical care and treatment & 37 & 34.1 to 39.1 \\
\hline Cause and origin & 24 & 21.9 to 26.3 \\
\hline Signs and symptoms & 21 & 19.3 to 23.6 \\
\hline
\end{tabular}

*Item-specific samples sizes varied slightly with $<5 \%$ missing for an item.

†Unprompted/open-ended/multiple selection item.

łUnprompted/open-ended/multiple selection item.

$\S$ Unprompted/open-ended/multiple selection item.

KAP, knowledge, attitudes and practices.

baseline was on convincing the population that 'Ebola is real' and overemphasised the connection of Ebola to bats and other animals. At the time, less emphasis was placed on human-to-human transmission of the virus, including sexual contact, which because of a potential transmission period of months prolonged the epidemic in all three West African countries. ${ }^{35}$ Our findings revealed that nearly all respondents already believed that Ebola existed in Sierra Leone, and they desired more in-depth information Ebola, especially on how to prevent Ebola infection. In Sierra Leone, the Ebola epidemiological data at the time of the survey suggested that funeral and burial practices involving the touching or washing of the dead were key drivers of transmission.
The KAP findings provided an important complement to the epidemiological data, and risk communication efforts were shifted to prioritise changing cultural norms on burials. Messaging and social mobilisation focused on promoting the benefits of adopting burial practice alternatives that are safe and accord dignity to the deceased. Likewise, as the epidemic continued to spread, the response system became overwhelmed and more people needed information on how to safely care for a sick household member as they waited for assistance. Messaging also focused on what people should do in their household as they waited for help. ${ }^{42}$

Previous public health interventions using the Health Belief Model provide strong evidence that individuals 
become motivated to adopt behaviour change when they perceive themselves to be at risk of contracting a disease and understand its severity if contracted. ${ }^{43}$ Going beyond risk perceptions, individuals are likely to take action when the perceived benefits of the action outweigh the perceived costs or barriers. Although most districts in Sierra Leone in August 2014, at the time of our survey, had active and increasing incidence of Ebola cases, only about half of respondents perceived some risk of Ebola acquisition. Most respondents linked their perceived risk of Ebola to eating or preparing bush meat. Such findings underscored the need to shift risk communication from animal-to-human transmission to human-to-human transmission, ${ }^{33-35}$ in line with the epidemiological profile at the time.

Communication of Ebola risk also requires messaging that appropriately balance fear appeals with protective actions to prevent infection. Early messaging highlighted the extremely high case fatality rates (up to 90\%) in past outbreaks in other countries ${ }^{33}$ without providing concrete prevention practices, which may have caused paralysing fear in the public. ${ }^{44}$ With the conclusion that death is nearly inevitable, the public may become less motivated to seek medical care if they are not confident in their ability to prevent possible infection of Ebola. In addition, misconceptions-such as the belief that Ebola can be prevented by bathing with salt and hot watermay have been a barrier to meaningful behaviour change and adoption of safer practices.

The high level of potential stigma and discriminatory attitudes towards Ebola survivors also may have served as a barrier to people seeking prompt medical care or calling to report a suspected death in the household. The findings therefore suggested that concerted efforts should be made to promote the acceptance of Ebola survivors and reduction of Ebola-related stigma and discrimination for survivors and households with affected family members. Following the KAP survey, efforts were made to portray survivors as 'Ebola Heroes' so as to create a more hopeful narrative that encourages people to seek early treatment and report suspected cases and deaths in the household. Radio and visual media such as television were leveraged to tell compelling survivor stories. Messaging developed immediately following the survey also focused on educating people about the possibility of viral persistence in semen, and messages have continued to evolve as the potential for longer duration of viral persistence in semen than other body fluids emerged. ${ }^{35}$ Nonetheless, a clear distinction was needed in relaying that survivors cannot transmit the disease through non-sexual physical contact.

In-depth interviews with Ebola survivors support our findings of discrimination by community members. ${ }^{45} 46$ Other assessments have also documented stigmatisation of healthcare workers who cared for patients with Ebola during the epidemic in West Africa. ${ }^{47} 48$ Similarly, Ebola-related stigma and xenophobic attitudes have been reported elsewhere outside of directly affected countries. ${ }^{26} 4950$
The KAP survey suggested that radio was the most preferred information channel and stakeholders used that finding to recommend that radio be maximally leveraged to reach mass audiences in the country with key messages using the local languages. Likewise, the survey suggested that health professionals and the Government of Sierra Leone were perceived to be the most trusted source of information on Ebola. Based on the findings of KAP, the relationship between health workers and communities and the role of health workers in stopping the outbreak were re-examined and reinforced.

Other behavioural theories also complemented our survey findings. The Social Cognitive Theory emphasises interpersonal social support and behaviour modelling in order to create an environment that enables and reinforces the promoted behaviours. ${ }^{41}$ While the survey showed that religious venues were the second highest source of information on Ebola, less than half of the respondents were receiving information through these kinds of community leaders, and traditional and religious leaders were mentioned infrequently as providing trusted information. Prior to August 2014, most religious leaders had not been formally engaged in the national Ebola response. Based on our survey findings, stakeholders recommended that Ebola response efforts work more closely with spiritual, traditional and religious leaders to improve the quality and quantity of information they were able to provide to communities, and to improve the mode of interactions between these leaders and communities so as to build trust in preventive behaviours especially around safe burials. Given the need to shift from customary funerals and burial ceremonies to safe and dignified medical burials, religious leaders were inherently identified as messengers to promote and role model safe burial practices.

Seeing that awareness of Ebola was high but that there remained ubiquitous misconceptions surrounding the disease, stakeholders recognised the need to provide accurate information on Ebola prevention-focusing on high-risk behaviours (contact with corpse and/ or bodily fluids), high-risk environments (households with sick persons or at traditional burial/funeral ceremonies) and accurate modes of transmission, as well as a supportive environment for Ebola survivors. These messages were integrated into future communication and intervention efforts, which were developed based on the KAP survey results. Our findings directly informed the Act Against Ebola-a comprehensive messaging guide ${ }^{42}$ developed by the national response that emphasised ways to prevent, detect and respond to the Ebola outbreak through the following themes: (1) take action to protect individuals and families in the home while waiting for help, (2) practice safe, dignified funerals and burials, (3) address misperceptions and myths about Ebola, (4) support and provide an accepting environment for survivors, (5) eliminate stigma and provide an accepting environment for Ebola 
service providers, and (6) promote unity, cooperation and hope in the fight against Ebola.

While the majority of respondents agreed that Ebola can be prevented by avoiding funerals or burials involving contact with corpses, epidemiological data from investigation of transmissions showed that traditional burials remained a substantial source of continued transmission in many communities. Social mobilisation efforts therefore needed to identify the barriers between knowledge and practice on this mode of transmission and preventive behaviour, and promote adequate social support for safe and dignified medical burials. Stakeholders knew that such social support should be channelled through existing channels of influence, trust, and respect-including religious leaders, traditional leaders, community elders and community health workers.

\section{Limitations}

Given the limited resources available and time-sensitivity of the emergency, it was not feasible to include all 14 districts in the sample. The nine districts were purposively selected based on the Ebola epidemiological trend at the time of the study design. However, the inclusion of enumeration areas from all four regions in the country mitigates the likelihood of sampling bias. Another limitation is that self-reported behaviours may not always be aligned with actual practices. It is possible that respondents may have provided socially desirable responses; especially due to the high awareness of Ebola and widespread sensitisation and education efforts at the time. Also, respondents from the same household may not have provided completely independent information as they lived together, although they were interviewed separately.

Notwithstanding these limitations, the baseline KAP study proved to be invaluable to the national Ebola response in Sierra Leone and the subregion. In addition, the results were used to develop a national social mobilisation strategy along with a monitoring and evaluation framework for assessing changes in KAP over time. The findings from Sierra Leone's August 2014 KAP survey helped to inform the critical next phase of the response during the worst Ebola outbreak in history. The survey reinforces both the feasibility and the importance of conducting KAP assessments as an early component of outbreak response.

\section{CONCLUSIONS}

Findings from this KAP assessment in the early phase of the unprecedented Ebola epidemic were important for identifying and addressing gaps in the Ebola-specific KAP. Other research has demonstrated that behaviour change played a key role in containing the spread of the epidemic. ${ }^{6}$ Utility of rapidly conducted KAP assessments provide practical opportunities for facilitating behaviour change during future outbreaks, and help prevent disease spread, human suffering and loss of life.

\section{Author affiliations}

${ }^{1}$ Division of Global Health Protection, Center for Global Health, US Centers for Disease Control and Prevention, Atlanta, Georgia, USA

${ }^{2}$ Research and Evaluation Department, FOCUS 1000, Freetown, Western Area, Sierra Leone

${ }^{3}$ Public Health Sciences Department, Karolinska Institutet, Stockholm, Sweden ${ }^{4}$ Sierra Leone Country Office, UNICEF, Freetown, Western Area, Sierra Leone ${ }^{5}$ Office of the Chief Executive Officer, FOCUS 1000, Freetown, Western Area, Sierra Leone

${ }^{6}$ Division of HIV/AIDS Prevention, Prevention Communication Branch, National Center for HIV/AIDS, Viral Hepatitis, STD, and TB Prevention, Centers for Disease Control and Prevention, Atlanta, Georgia, USA

${ }^{7}$ Sierra Leone Country Office, Catholic Relief Services, Freetown, Western Area, Sierra Leone

${ }^{8}$ Health Education Division, Ministry of Health and Sanitation, Freetown, Western Area, Sierra Leone

${ }^{9}$ Office of the Director, National Center for HIV/AIDS, Viral Hepatitis, STD, and TB Prevention, Centers for Disease Control and Prevention, Atlanta, Georgia, USA

Acknowledgements The authors thank the 1413 Sierra Leoneans who were willing to participate in the assessment in the midst of the outbreak. The authors also thank the data collection teams for their diligent efforts in ensuring data quality. The authors also thank the Government of Sierra Leone, national and international partners in the response who translated the baseline KAP findings into practical strategies and life-saving interventions. The authors thank several colleagues for their various support to the success of the assessment. From MoHS: Brima Kargbo, Amara Jambai, SAS Kargbo, Sarian Kamara, Foday Dafae, and Alusine Kamara. From FOCUS 1000: Samuel Abu Pratt, George Saquee, Victoria Squire, Christiana Jengor, Ramatu Jalloh, Aiah Sinah, Fatmata Kalokoh, Bridgette Lewis, Osman Sesay. From CDC: Peter Kilmarx, Leigh Ann Miller, and Leslie Hausman.

Contributors MFJ, PS, RM, MBJ, MD and YS led the conception and design of the survey. PS, MBJ, MFJ, MD, SS, LC, and SG supported the training and supervision of data collection teams. PS led the data analysis with support from MFJ. WL conducted separate analysis of all data to ensure consistency. RB, JM, VB, ND conducted careful reviews of all analysis. All coauthors substantially contributed to the interpretation of the results and to the preparation and writing of the manuscript.

Funding FOCUS 1000 received funding to support data collection from UNICEF and Catholic Relief Services.

Disclaimer The findings and conclusions in this manuscript are those of the authors, and do not necessarily represent an official position of the US centers for Disease Control and Prevention.

Competing interests None declared.

Ethics approval Sierra Leone Ethics and Scientific Review Committee in the Ministry of Health and Sanitation.

Provenance and peer review Not commissioned; externally peer reviewed.

Data sharing statement Data sharing agreement has been developed for the Ebola KAP Assessment in Sierra Leone. All requests to access the data must be processed through the multipartner data sharing mechanism. All data accessibility requests should be directed to the corresponding author.

Open Access This is an Open Access article distributed in accordance with the Creative Commons Attribution Non Commercial (CC BY-NC 4.0) license, which permits others to distribute, remix, adapt, build upon this work non-commercially, and license their derivative works on different terms, provided the original work is properly cited and the use is non-commercial. See: http://creativecommons.org/ licenses/by-nc/4.0/

(c) Article author(s) (or their employer(s) unless otherwise stated in the text of the article) 2017. All rights reserved. No commercial use is permitted unless otherwise expressly granted.

\section{REFERENCES}

1. World Health Organization. Ebola situation reports. http://apps.who. int/Ebola/Ebola-situation-reports (accessed Apr 2016).

2. Sierra Leone Ministry of Health and Sanitation. Ebola virus disease - situation report http://health.gov.sl/wp-content/uploads/2014/08/ Ebola-Update-August-14-2014.pdf (accessed Apr 2016). 
3. World Health Organization. Report of the Ebola interim assessment panel. http://www.who.int/csr/resources/publications/Ebola/Ebolapanel-report/en (accessed Apr 2016).

4. Moon S, Sridhar D, Pate MA, et al. Will Ebola change the game? Ten essential reforms before the next pandemic. The report of the Harvard-LSHTM Independent Panel on the Global Response to Ebola. Lancet 2015;386:2204-21.

5. Sierra Leone Ministry of Health and Sanitation. National communication strategy for Ebola response in Sierra Leone http:// Ebolacommunicationnetwork.org/wp-content/uploads/2014/10/ National-Ebola-Communication-Strategy_FINAL.pdf (accessed Apr 2016).

6. Fast SM, Mekaru S, Brownstein JS, et al. The role of social mobilization in controlling ebola virus in lofa county, liberia. PLOS Curr 2015;7.

7. Laverack G, Manoncourt E. Key experiences of community engagement and social mobilization in the Ebola response. Glob Health Promot 2016;23:79-82.

8. Bedrosian SR, Young CE, Smith LA, et al. Lessons of Risk Communication and Health Promotion - West Africa and United States. MMWR Suppl 2016;65:68-74.

9. Santibañez S, Siegel V, O'Sullivan M, et al. Health communications and community mobilization during an Ebola response: partnerships with community and faith-based organizations. Public Health Rep 2015;130:128-33.

10. Smith HL. On the limited utility of KAP-style survey data in the practical epidemiology of AIDS, with reference to the AIDS epidemic in Chile. Health Transit Rev 1993;3:1-16.

11. Caldwell JC, Lane JM, Caraël M, et al. Forum: On the limited utility of KAP-style survey data in the practical epidemiology of AIDS. Health Transit Rev 1993;3:205-16.

12. Wilson D, Mehryar A. The role of AIDS knowledge, attitudes, beliefs and practices research in sub-Saharan Africa. AIDS 1991;5(Suppl 1):177-81.

13. Kobayashi M, Beer KD, Bjork A, et al. Community Knowledge, Attitudes, and Practices Regarding Ebola Virus Disease - Five Counties, Liberia, September-October, 2014. MMWR Morb Mortal Wkly Rep 2015;64:714-8.

14. Buli BG, Mayigane LN, Oketta JF, et al. Misconceptions about Ebola seriously affect the prevention efforts: KAP related to Ebola prevention and treatment in Kouroussa Prefecture, Guinea. Pan Afr Med J 2015;22(Suppl 1):11.

15. Li W, Jalloh MF, Bunnell R, et al. Public Confidence in the Health Care System 1 Year After the Start of the Ebola Virus Disease Outbreak - Sierra Leone, July 2015. MMWR Morb Mortal Wkly Rep 2016;65:538-42.

16. Patel U, Pharr JR, Ihesiaba C, et al. Ebola Outbreak in Nigeria: Increasing Ebola Knowledge of Volunteer Health Advisors. Glob J Health Sci 2015;8:72-8.

17. Yamanis T, Nolan E, Shepler S. Fears and Misperceptions of the Ebola Response System during the 2014-2015 Outbreak in Sierra Leone. PLoS Negl Trop Dis 2016;10:e0005077.

18. Iliyasu G, Ogoina D, Otu AA, et al. A Multi-Site Knowledge Attitude and Practice Survey of Ebola Virus Disease in Nigeria. PLoS One 2015;10:e0135955.

19. Jiang $H$, Shi GQ, Tu WX, Wx T, et al. Rapid assessment of knowledge, attitudes, practices, and risk perception related to the prevention and control of Ebola virus disease in three communities of Sierra Leone. Infect Dis Poverty 2016;5:53.

20. Olowookere SA, Abioye-Kuteyi EA, Adepoju OK, et al. Knowledge, Attitude, and Practice of Health Workers in a Tertiary Hospital in Ile-Ife, Nigeria, towards Ebola Viral Disease. J Trop Med 2015;2015:1-6.

21. Adongo PB, Tabong PT, Asampong E, et al. Beyond Knowledge and Awareness: Addressing Misconceptions in Ghana's Preparation towards an Outbreak of Ebola Virus Disease. PLoS One 2016;11:e0149627.

22. Otu A, Ebenso B, Okuzu O, et al. Using a mHealth tutorial application to change knowledge and attitude of frontline health workers to Ebola virus disease in Nigeria: a before-and-after study. Hum Resour Health 2016;14:5.

23. Aminu K, Jegede AS. Perception and attitude towards Ebola Virus Disease among traditional healers in Ibadan, Nigeria. Afr J Med Med Sci 2015;44:205-12.

24. Idris BJ, Inem V, Balogun M. Comparing the knowledge, attitude and practices of health care workers in public and private primary care facilities in Lagos State on Ebola virus disease. Pan Afr Med J 2015;22(Suppl 1):19.
25. Mohamed MMG, Shwaib HM, Fahim MM, et al. Ebola hemorrhagic fever under scope, view of knowledge, attitude and practice from rural Sudan in 2015. J Infect Public Health 2017;10:287-94.

26. Prati G, Pietrantoni L. Knowledge, Risk Perceptions, and Xenophobic Attitudes: Evidence from Italy During the Ebola Outbreak. Risk Anal 2016;36:2000-10.

27. Petrie KJ, Faasse K, Thomas MG. Public Perceptions and Knowledge of the Ebola Virus, Willingness to Vaccinate, and Likely Behavioral Responses to an Outbreak. Disaster Med Public Health Prep 2016;10:674-80.

28. Rolison JJ, Hanoch Y. Knowledge and risk perceptions of the Ebola virus in the United States. Prev Med Rep 2015;2:262-4.

29. Holakouie-Naieni K, Ahmadvand A, Raza O, et al. Assessing the Knowledge, Attitudes, and Practices of Students Regarding Ebola Virus Disease Outbreak. Iran J Public Health 2015:44:1670-6.

30. Ahmad A, Khan MU, Jamshed SQ, et al. Are healthcare workers ready for Ebola? An assessment of their knowledge and attitude in a referral hospital in South India. J Infect Dev Ctries 2016;10:747-54.

31. International Federation of Red Cross and Red Crescent Societies. Knowledge, attitudes and practices survey on the Ebola Virus Disease (EVD) - Kailahun and Kenema Districts, Sierra Leone. Freetown: IFRC, 2014.

32. Gillespie AM, Obregon R, El Asawi R, et al. Social Mobilization and Community Engagement Central to the Ebola Response in West Africa: Lessons for Future Public Health Emergencies. Glob Health Sci Pract 2016;4:626-46.

33. Lawrence P, Danet N, Reynard O, et al. Human transmission of Ebola virus. Curr Opin Virol 2017;22:51-8.

34. Hageman JC, Hazim C, Wilson K, et al. Infection Prevention and Control for Ebola in Health Care Settings - West Africa and United States. MMWR Supp/ 2016;65:50-6.

35. Deen GF, Broutet N, Xu W, et al. Ebola RNA Persistence in Semen of Ebola Virus Disease Survivors - Final Report. N Engl J Med 2017;377:1428-37.

36. Statistics Sierra Leone. National population and housing census 2004. https://www.statistics.sl/wp-content/uploads/2016/06/2004 population_and_housing_census_tables.pdf (accessed Jul 2014).

37. Flynn A, Tremblay PF, Rehm J, et al. A modified random walk doorto-door recruitment strategy for collecting social and biological data relating to mental health, substance use, addiction, and violence problems in a Canadian community. Int J Alcohol Drug Res 2013:2:7-16

38. Dare OO, Cleland JG. Reliability and validity of survey data on sexual behaviour. Health Transit Rev 1994;4(Suppl 1):93-110.

39. Cleland J, Boerma JT, Carael M, et al. Monitoring sexual behaviour in general populations: a synthesis of lessons of the past decade. Sex Transm Infect 2004;80(Suppl 2):ii1-7.

40. Mertens T, Caraël M, Sato P, et al. Prevention indicators for evaluating the progress of national AIDS programmes. AIDS 1994:8:1359-70.

41. World Health Organization. National AIDS programmes: A guide to monitoring and evaluation. http://www.who.int/hiv/pub/me/pubnap/ en (accessed Jul 2014).

42. Sierra Leone Ministry of Health and Sanitation. Act against Ebola. Freetown: Ministry of Health and Sanitation, 2014.

43. Glanz K, Rimer BK, Viswanath K. Health behavior and health education theory, research, and practice. San Francisco: JosseyBass, 2008

44. Lamunu M, Olu OO, Bangura J, et al. Epidemiology of Ebola Virus Disease in the Western Area Region of Sierra Leone, 2014-2015. Front Public Health 2017:5:33.

45. Karafillakis E, Jalloh MF, Nuriddin A, et al. 'Once there is life, there is hope' Ebola survivors' experiences, behaviours and attitudes in Sierra Leone, 2015. BMJ Glob Health 2016:1:e000108.

46. De Roo A, Ado B, Rose B, et al. Survey among survivors of the 1995 Ebola epidemic in Kikwit, Democratic Republic of Congo: their feelings and experiences. Trop Med Int Health 1998;3:60-4.

47. Chan BP, Daly ER, Talbot EA. Workplace safety concerns among coworkers of responder returning from Ebola-affected Country. Emerg Infect Dis 2015;21:2077-9.

48. Hobbs C, Myles P, Pritchard C. A content analysis of the UK press response to the diagnosis of Ebola in a British healthcare worker. $J$ Public Health 2016 (Epub ahead of print: 27 Sep 2017).

49. Koralek T, Runnerstrom MG, Brown BJ, et al. Lessons from Ebola: sources of outbreak information and the associated impact on UC Irvine and Ohio University college students. PLoS Curr 2016;8.

50. Kim HS, Sherman DK, Updegraff JA. Fear of Ebola: the influence of collectivism on xenophobic threat responses. Psychol Sci 2016;27:935-44. 